\title{
Influência da estrutura molecular dos policarboxilatos na hidratação do cimento Portland
}

\author{
influence of polycarboxylate molecular structure on \\ Portland cement hydration
}

\section{Carolina Martínez Rojas Maria Alba Cincotto}

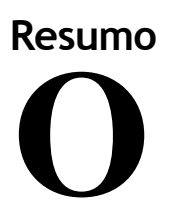

objetivo deste trabalho é apresentar os dados de literatura que enfatizam a influência da estrutura molecular de policarboxilatos na hidratação do cimento, estudada por ensaios de calor de hidratação, tempos de pega e análise termogravimétrica em pastas de cimento. Com essa mesma metodologia foram avaliados dois policarboxilatos, agente ativo de dois aditivos nacionais cujas estruturas moleculares diferem no tamanho das cadeias laterais. Tanto os dados da literatura quanto os resultados dos ensaios realizados mostram que o fator da estrutura molecular do policarboxilato que determina o retardo da pasta de cimento é a densidade de carga aniônica presente no sistema, a qual é maior quanto menor a densidade de cadeias laterais.

Adicionalmente, se comparada a influência na hidratação do cimento de policarboxilatos com igual densidade de cadeias laterais, porém, de tamanhos diferentes, utilizados em igual quantidade em massa, observa-se que aqueles com cadeias laterais menores geram maior retardo.

Palavras-chave: Policarboxilato. Estrutura molecular. Hidratação. Cimento Portland CPV. Calorimetria isotérmica. Termogravimetria.

\begin{abstract}
This study aims to present data from the literature that emphasize the influence of the polycarboxylate molecular structure on cement hydration, by isothermal calorimetry, setting times and thermogravimetric analysis of cement pastes. Using the same methodology, two Brazilian poly-carboxylates with different molecular structures, used on the production of Brazilian admixtures, were investigated. The literature data, as well as the test results, show that the main factor of the polycarboxylate molecular structure related to its retarding effect is the anionic charge density present in the system, which is higher when the side chain density is lower. In the case of polycarboxylates with equal side chain density, those with shorter side chains lead to higher retardation when used in the same mass quantity.
\end{abstract}

Carolina Martínez Rojas Universidade de São Paulo São Paulo - SP - Brasil

Maria Alba Cincotto Universidade de São Paulo São Paulo - SP - Brasil

Recebido em 18/09/12 Aceito em 31/07/13

Keywords: Polycarboxylate. Molecular structure. Hydration. Portland cement. Calorimetry. Thermogravimetric analysis. 


\section{Introdução}

O presente trabalho discute a influência da estrutura molecular de policarboxilatos na hidratação do cimento, estudada por ensaios de calor de hidratação, tempos de pega e análise termogravimétrica em pastas de cimento.

Os aditivos dispersantes à base de policarboxilato, aplicados como superplastificantes ou redutores de água de alto desempenho, possuem capacidade de dispersão superior à dos aditivos dispersantes tradicionais, sendo possível, a partir de sua utilização, a produção de concretos com características especiais, formulados, dependendo das exigências do projeto, para atingir maiores resistências mecânicas e melhores características de aplicação, com diminuição nos tempos de lançamento e ganhos em durabilidade. A disponibilidade no mercado de concretos de alto desempenho tem viabilizado projetar estruturas com maiores possibilidades do ponto de vista arquitetônico e com melhor aproveitamento do espaço por empregar elementos estruturais de menores dimensões.

Os policarboxilatos propiciam a dispersão das partículas de cimento, aumentando sua eficiência como ligante. Assim, além dos requisitos tecnológicos, seu emprego pode ser uma estratégia para diminuição da emissão de $\mathrm{CO}_{2}$ derivada da indústria do cimento, responsável pelos $5 \%$ das emissões globais, a partir da produção de concretos com menores consumos de cimento, que atendam aos requisitos de resistência e durabilidade específicos de cada projeto.

Os superplastificantes melhoram a trabalhabilidade de pastas, argamassas e concretos por propiciar a dispersão das partículas do cimento por forças de repulsão eletrostáticas ou estéricas. Consequentemente, têm efeitos sobre as reações de hidratação, retardando-as, assim como os tempos de pega (FARRINGTON, 2007; KOIZUMI; UMEMURA; TSUYUKI, 2007; LOTHENBACH; WINNEFELD; FIGI, 2007; MACAR; CHAN, 2007; POURCHET et al., 2007; RÖßLER; MÖSER; STARK, 2007; SAKAI et al., 2006; ZINGG, 2008).

Há também influência sobre a microestrutura que se forma no estado fresco. Na presença dos PCs não há aglomeração inicial, e a tensão de cisalhamento e a viscosidade da pasta são diminuídas, pois há modificação da distribuição das partículas, com aumento da área específica superficial que entra em contacto com a água. Os hidratos iniciais não se depositam homogeneamente ao redor das partículas, formando grãos de Hadley, mas estão predominantemente dispersos na fase líquida intersticial, principalmente a etringita (ZINGG et al., 2008a).

Aditivos à base de policarboxilato apresentam-se como uma alternativa versátil para atender a diversos requisitos, já que o policarboxilato-base dos aditivos superplastificantes pode ser sintetizado de forma a obterem-se diversas estruturas moleculares, com um desempenho específico.

\section{Aditivos à base de policarboxilato}

Os aditivos dispersantes à base de policarboxilato (PC) são polímeros de estrutura combinada, constituída por uma cadeia principal que se adsorve às partículas de cimento e cadeias laterais neutras, que, por sua vez, estabilizam o sistema por impedimento estérico, devido à resistência à interação, sob determinadas circunstâncias, das cadeias dos polímeros adsorvidos em duas partículas diferentes (FLATT et al., 2009).

A cadeia principal é constituída pela polimerização do monômero ácido acrílico ou metacrílico, carregada negativamente pelos grupos carboxílicos presentes. Parte desse grupo funcional é esterificada por poliálcoois, que se constituem nas cadeias laterais de óxido de polietileno. Na síntese do PC, objetivando determinado desempenho, são considerados o comprimento da cadeia principal, o comprimento da cadeia lateral e a relação molar entre as cargas da cadeia principal e o número de cadeias laterais. O comprimento da cadeia principal caracteriza o polímero pela massa molecular e capacidade de polidispersão. $\mathrm{Na}$ Figura 1 é apresentado um modelo da estrutura molecular dos policarboxilatos éster (PCE).

A molécula do policarboxilato-éster (PCE) adsorve-se pelos grupos carboxílicos na superfície das partículas do cimento, ou de seus produtos de hidratação, numa interação de origem eletrostática. As cadeias laterais, por sua vez, apresentam grande afinidade pela solução presente nos sistemas cimentícios nas idades iniciais da hidratação, dispersando as partículas por repulsão estérica gerada pelos grupos éter da cadeia lateral (ALONSO et al., 2007; GRIESSER, 2002; HUI et al., 2007; PLANK; SACHSENHAUSER, 2009). Na Figura 2 é apresentado de forma esquemática esse mecanismo.

Dois parâmetros determinam a capacidade de o aditivo adsorver-se às partículas e seu desempenho: 
(a) a densidade de carga aniônica da macromolécula e sua interação eletrostática com o cimento, a qual é proporcional à quantidade de grupos carboxílicos não esterificados; e

(b) o comprimento das cadeias laterais, responsável pela espessura da camada de polímero que se forma em volta dos grãos e pelo tipo de interação das cadeias dos polímeros adsorvidos em duas partículas diferentes, ambos resultando na repulsão estérica entre elas (PLANK et al., 2008;
PLANK; SACHSENHAUSER, 2009; WINNEFELD et al., 2007a).

Tem sido verificado que, de forma geral, das fases do cimento, o $\mathrm{C}_{3} \mathrm{~A}$ e o $\mathrm{C}_{4} \mathrm{AF}$ adsorvem uma quantidade maior de policarboxilato do que o $\mathrm{C}_{3} \mathrm{~S}$ e o $\mathrm{C}_{2} \mathrm{~S}$; assim, a quantidade máxima de aditivo adsorvida por determinado cimento depende da proporção relativa dessas fases presentes no clínquer (CHANDRA; BENSTED; BARNES, 2002; YOSHIOKA et al., 2002).

\section{Figura 1 - Policarboxilato éster}

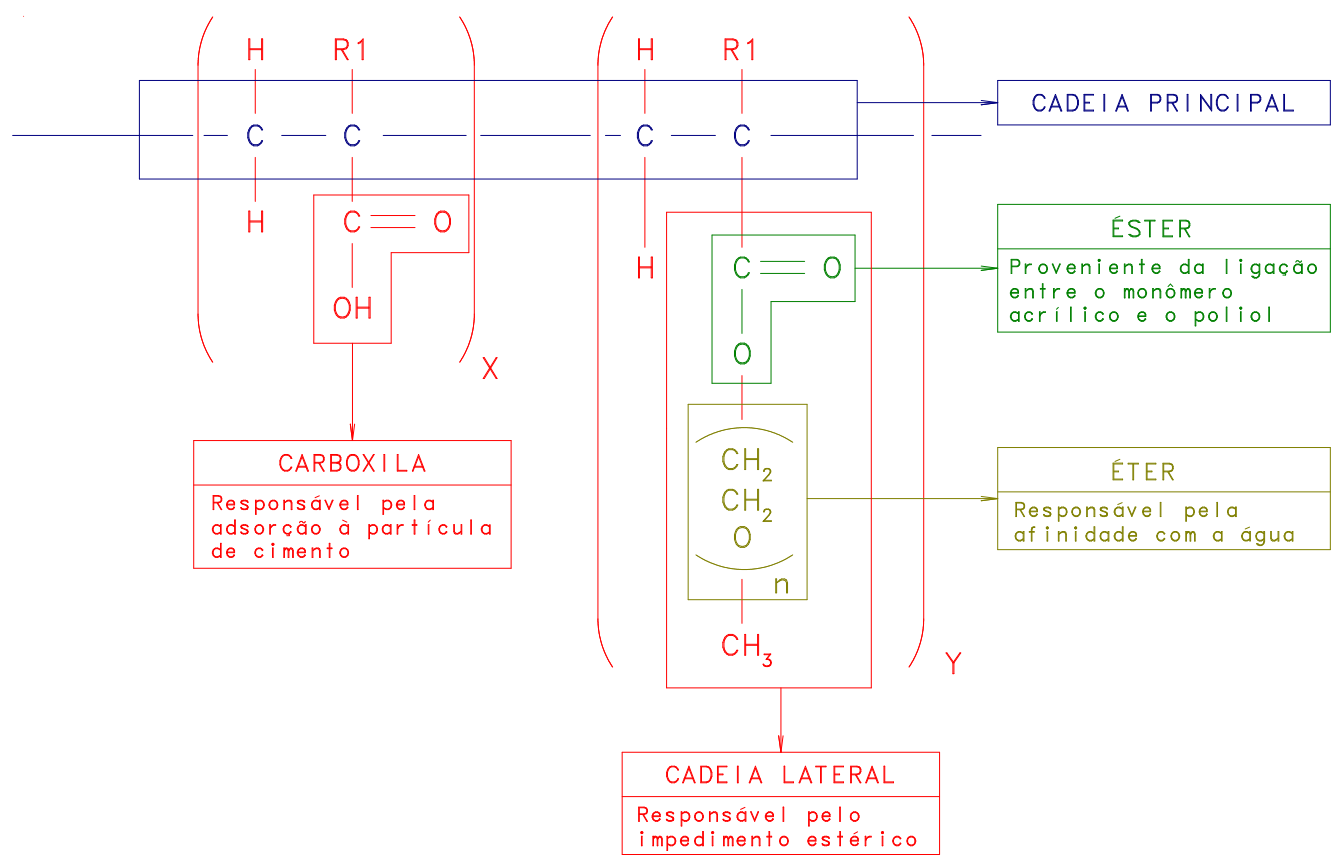

Figura 2 - Interação polímero-cimento

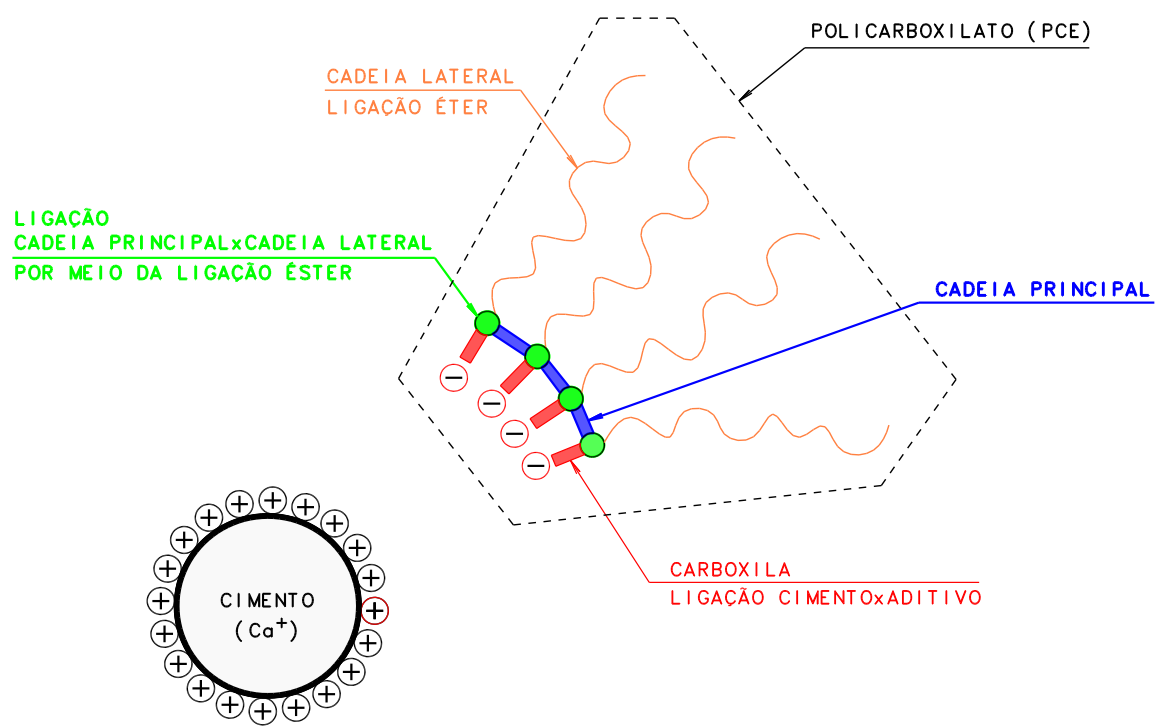




\section{Influência da estrutura molecular dos aditivos à base de policarboxilato na hidratação do cimento}

Os estudos realizados sobre a influência desses aditivos na hidratação do cimento indicam, de forma geral, um efeito retardador devido à formação da camada que envolve os grãos de cimento, a qual impede o contato das partículas com a água e sua dissolução (LOTHENBACH; WINNEFELD; FIGI, 2007; PUERTAS; VAZQUEZ, 2001; UCHIKAWA; SAWAKI; HANEHARA, 1997).

$\mathrm{O}$ retardo foi primeiramente atribuído à formação de composto complexo entre as moléculas do policarboxilato e o íon cálcio da solução da pasta de cimento (PUERTAS; VAZQUEZ, 2001; UCHIKAWA; SAWAKI; HANEHARA, 1997). Em pesquisa mais recente não foi verificada nenhuma alteração na concentração do íon cálcio da água do poro das pastas, confirmando que o retardo é, de fato, consequente à adsorção do aditivo na superfície das partículas, e o efeito fluidificante, por dispersão estérica ou eletroestérica gerada pela densidade de cargas na molécula do aditivo (LOTHENBACH; WINNEFELD; FIGI, 2007).

Estudos recentes abordam a influência da estrutura molecular do PCE, uma vez que esses produtos diferem pela densidade de carga aniônica e comprimento das cadeias laterais. Alguns autores têm verificado que o grau no qual os aditivos à base de policarboxilato retardam a pega $\mathrm{e}$ endurecimento dos produtos à base de cimento depende da estrutura molecular do aditivo utilizado, e, de forma geral, quanto maior a densidade de carga aniônica do aditivo utilizado (comprimento e densidade de cadeias laterais pequenas), maior será o retardo gerado (MORATTI; MAGAROTTO; MANTELLATO, 2011; POURCHET et al., 2007; SCHMIDT et al., 2011; WINNEFELD et al., 2007b; ZINGG et al., 2009; ZINGG, 2008).

Entre as pesquisas realizadas para avaliação da influência da estrutura molecular do aditivo na hidratação do cimento, com diferentes teores de $\mathrm{C}_{3} \mathrm{~A}$, determinada por calorimetria isotérmica, encontram-se os trabalhos de Winnefeld et al. (2007b) e Zingg et al. (2009), cujos resultados estão apresentados nas Tabelas 1 e 2 . Winnefeld $e t$ al. (2007a) compararam diferentes estruturas moleculares, com o polímero de ácido polimetacrílico, sem cadeias laterais acopladas. Schmidt et al. (2011) compararam o efeito no tempo de pega e calor de hidratação, em concreto autoadensável, de dois aditivos com cadeias laterais de igual tamanho, porém diferente densidade de carga aniônica, na quantidade necessária para se atingir o mesmo abatimento, ou seja, $0,62 \%$ de sólidos do aditivo de menor densidade de carga (PCE LC) aniônica e 0,38\% de sólidos do aditivo de maior densidade de carga aniônica (PCE HC), em relação à massa do cimento; e também quando adicionados em igual quantidade de sólidos, isto é, 0,38\%. Moratti, Magarotto e Montellano (2011) avaliaram a influência de dois aditivos com tamanho e quantidade de cadeias laterais diferentes, dosados em igual teor, em relação à massa de cimento, na duração do período de indução e na quantidade de C-S-H e portlandita formados após $18 \mathrm{~h}$ e $24 \mathrm{~h}$ de hidratação, determinada por termogravimetria. 
Tabela 1 - Influência da estrutura molecular de PCEs na hidratação do cimento - dados da literatura

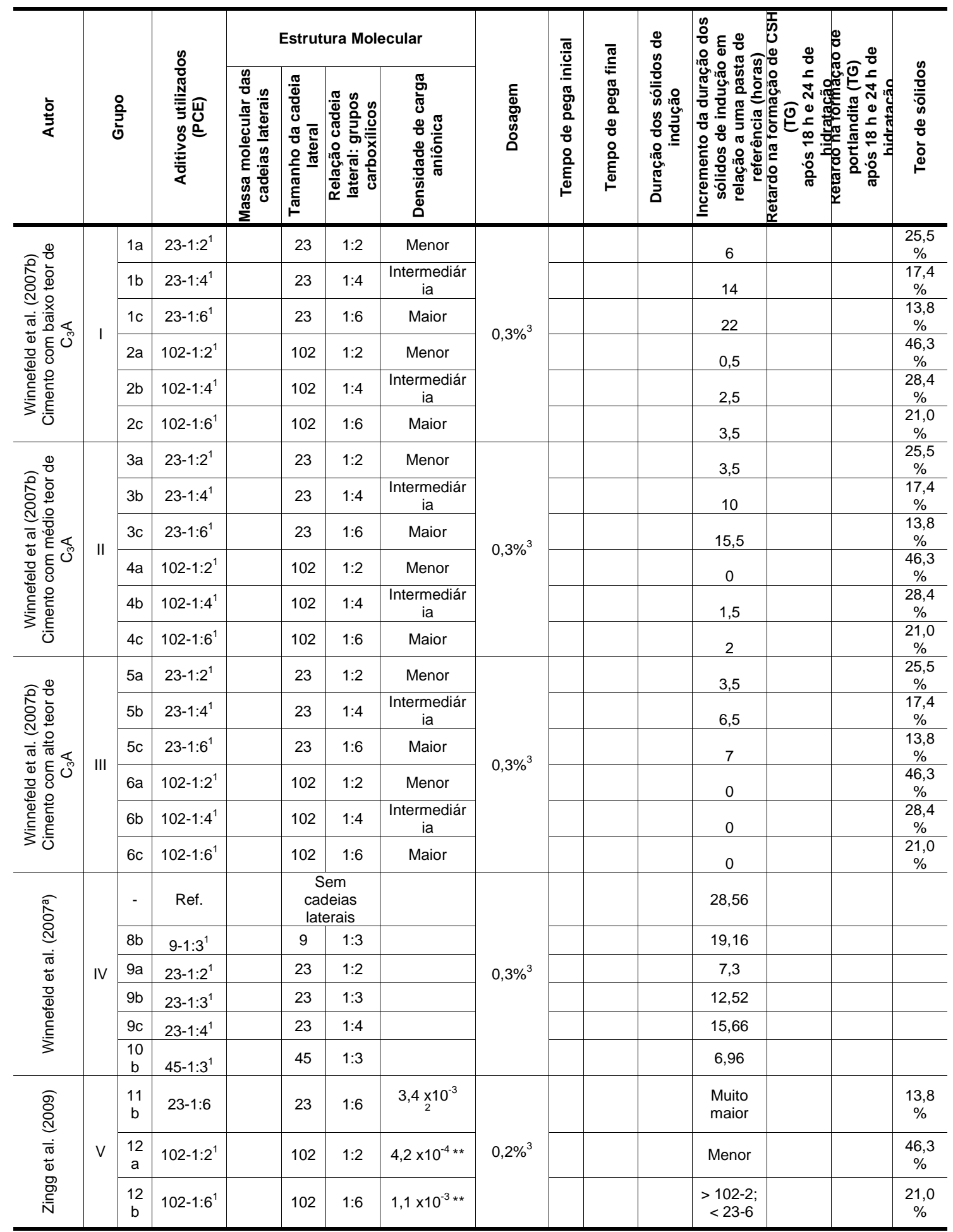

Nota: ${ }^{1} \mathrm{Na}$ identificação dos aditivos, o primeiro número se refere ao tamanho da cadeia lateral, e a sequência de números, à continuação à relação cadeia lateral: grupos carboxílicos; assim, um aditivo identificado como 23-1:2 referese a um polímero com tamanho de cadeia lateral igual a 23 e com uma cadeia lateral para cada 2 grupos carboxílicos livres. ${ }^{2}$ Número de lugares com carga aniônica por molécula. ${ }^{3}$ Porcentagem de sólidos do aditivo adicionada ao sistema em relação à massa do cimento. ${ }^{4}$ Cadeia lateral de igual comprimento. 
Tabela 1 - Influência da estrutura molecular de PCEs na hidratação do cimento - dados da literatura (continuação)

\begin{tabular}{|c|c|c|c|c|c|c|c|c|c|c|c|c|c|c|c|}
\hline \multirow[b]{2}{*}{ 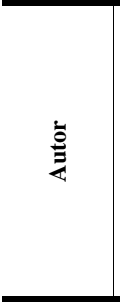 } & \multirow{2}{*}{\multicolumn{2}{|c|}{ 总 }} & \multirow{2}{*}{ 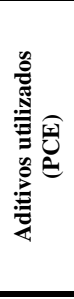 } & \multicolumn{4}{|c|}{ Estrutura Molecular } & \multirow[b]{2}{*}{ 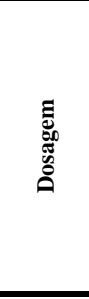 } & \multirow{2}{*}{ 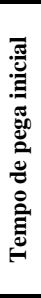 } & \multirow{2}{*}{ 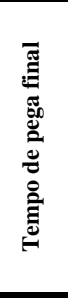 } & \multirow{2}{*}{ 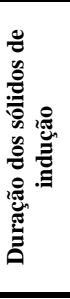 } & \multirow{2}{*}{\multicolumn{2}{|c|}{ 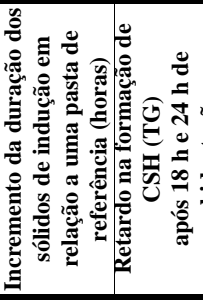 }} & \multirow{2}{*}{ 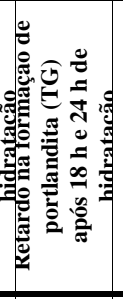 } & \multirow{2}{*}{ 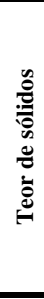 } \\
\hline & & & & 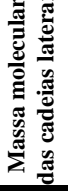 & 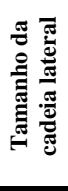 & 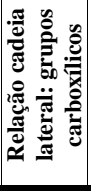 & 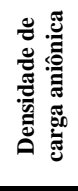 & & & & & & & & \\
\hline \multirow{4}{*}{ 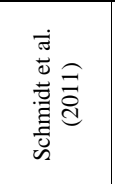 } & \multirow{4}{*}{$\begin{array}{l}\text { V } \\
\text { I }\end{array}$} & 13 & $\mathrm{LC}^{4}$ & & & & Menor & $0,62 \%^{3}$ & $>$ & $>$ & $>$ & & & & \\
\hline & & 14 & $\mathrm{HC}^{4}$ & & & & Maior & $0,38 \%^{3}$ & $<$ & $<$ & $<$ & & & & \\
\hline & & 15 & $\mathrm{LC}^{4}$ & & & & Menor & $0,38 \%^{3}$ & $<$ & \multirow{2}{*}{ Igual } & \multirow{2}{*}{ Igual } & & & & \\
\hline & & 15 & $\mathrm{HC}^{4}$ & & & & Maior & $0,38 \%^{3}$ & $>$ & & & & & & \\
\hline \multirow{2}{*}{ 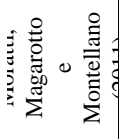 } & \multirow{2}{*}{$\begin{array}{l}\text { V } \\
\text { II }\end{array}$} & 16 & PCE1 & 500 & & & Maior & \multirow{2}{*}{ Igual } & - & - & $>$ & & $>$ & $>$ & $\begin{array}{c}30,0 \\
\%\end{array}$ \\
\hline & & 16 & PCE2 & 3000 & & & Menor & & - & - & $>$ & & $<$ & $<$ & $\begin{array}{c}46,0 \\
\%\end{array}$ \\
\hline
\end{tabular}

Nota: ${ }^{1} \mathrm{Na}$ identificação dos aditivos, o primeiro número se refere ao tamanho da cadeia lateral, e a sequência de números, à continuação à relação cadeia lateral: grupos carboxílicos; assim, um aditivo identificado como 23-1:2 referese a um polímero com tamanho de cadeia lateral igual a 23 e com uma cadeia lateral para cada 2 grupos carboxílicos livres. ${ }^{2}$ Número de lugares com carga aniônica por molécula. ${ }^{3}$ Porcentagem de sólidos do aditivo adicionada ao sistema em relação à massa do cimento. ${ }^{4}$ Cadeia lateral de igual comprimento.

Tabela 2 - Influência da estrutura molecular de aditivos à base de policarboxilato em sua capacidade para se adsorver na superfície do cimento - dados da literatura

\begin{tabular}{|c|c|c|c|c|c|c|c|c|}
\hline \multirow[b]{2}{*}{ Autor } & \multirow{2}{*}{\multicolumn{2}{|c|}{$\stackrel{\circ}{\Xi}$}} & \multirow[b]{2}{*}{$\begin{array}{c}\text { Aditivos } \\
\text { utilizados } \\
\text { (PCE) }\end{array}$} & \multicolumn{2}{|c|}{ Estrutura molecular } & \multirow[b]{2}{*}{ Dosagem } & \multirow[b]{2}{*}{$\begin{array}{l}\text { Teor de } \\
\text { sólidos }\end{array}$} & \multirow{2}{*}{$\begin{array}{c}\text { Teor de aditivo } \\
\text { adsorvido } \\
\text { (adsorvido/ } \\
\text { adicionado)x100 }\end{array}$} \\
\hline & & & & $\begin{array}{c}\text { Tamanho } \\
\text { da cadeia } \\
\text { lateral } \\
\end{array}$ & $\begin{array}{c}\text { Densidade de } \\
\text { carga } \\
\text { aniônica } \\
\end{array}$ & & & \\
\hline \multirow{6}{*}{ 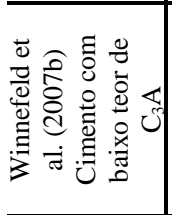 } & \multirow{6}{*}{ I } & $1 \mathrm{a}$ & $23-1: 2 *$ & 23 & Menor & \multirow{6}{*}{$0,2 \% * * *$} & $25,5 \%$ & $22,5 \%$ \\
\hline & & $1 \mathrm{~b}$ & $23-1: 4^{*}$ & 23 & Intermediária & & $17,4 \%$ & $47,5 \%$ \\
\hline & & $1 \mathrm{c}$ & $23-1: 6^{*}$ & 23 & Maior & & $13,8 \%$ & $62,5 \%$ \\
\hline & & $2 a$ & $102-1: 2^{*}$ & 102 & Menor & & $46,3 \%$ & $0,00 \%$ \\
\hline & & $2 b$ & $102-1: 4^{*}$ & 102 & Intermediária & & $28,4 \%$ & $35,0 \%$ \\
\hline & & $2 \mathrm{c}$ & $102-1: 6^{*}$ & 102 & Maior & & $21,0 \%$ & $60,0 \%$ \\
\hline \multirow{6}{*}{ 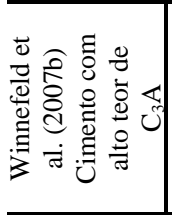 } & \multirow{6}{*}{ II } & $3 a$ & $23-1: 2 *$ & 23 & Menor & \multirow{6}{*}{$0,2 \% * * *$} & $25,5 \%$ & $37,5 \%$ \\
\hline & & $3 b$ & $23-1: 4^{*}$ & 23 & Intermediária & & $17,4 \%$ & $65,0 \%$ \\
\hline & & $3 c$ & $23-1: 6^{*}$ & 23 & Maior & & $13,8 \%$ & $77,5 \%$ \\
\hline & & $4 \mathrm{a}$ & $102-1: 2^{*}$ & 102 & Menor & & $46,3 \%$ & $37,5 \%$ \\
\hline & & $4 \mathrm{~b}$ & $102-1: 4^{*}$ & 102 & Intermediária & & $28,4 \%$ & $42,5 \%$ \\
\hline & & $4 c$ & $102-1: 6^{*}$ & 102 & Maior & & $21,0 \%$ & $75,0 \%$ \\
\hline \multirow{10}{*}{ 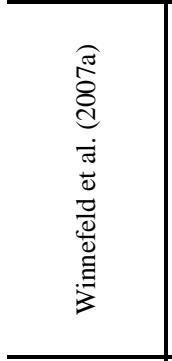 } & \multirow{10}{*}{$\begin{array}{c}\text { II } \\
\text { I }\end{array}$} & 5 & Ref. & \multicolumn{2}{|c|}{ Sem cadeias laterais } & \multirow{10}{*}{$0,2 \% * * *$} & & $100,0 \%$ \\
\hline & & $6 a$ & $91: 2^{*}$ & 9 & $1: 2$ & & & $56,0 \%$ \\
\hline & & $6 b$ & $91: 3^{*}$ & 9 & $1: 3$ & & & $74,0 \%$ \\
\hline & & $6 c$ & $91: 4^{*}$ & 9 & $1: 4$ & & & $85,0 \%$ \\
\hline & & $7 \mathrm{a}$ & $231: 2^{*}$ & 23 & $1: 2$ & & & $41,0 \%$ \\
\hline & & $7 b$ & $231: 3^{*}$ & 23 & $1: 3$ & & & $59,0 \%$ \\
\hline & & $7 \mathrm{c}$ & $231: 4^{*}$ & 23 & $1: 4$ & & & $77,0 \%$ \\
\hline & & $8 \mathrm{a}$ & $451: 2^{*}$ & 45 & $1: 2$ & & & $37,0 \%$ \\
\hline & & $8 \mathrm{~b}$ & $451: 3 *$ & 45 & $1: 3$ & & & $56,0 \%$ \\
\hline & & $8 \mathrm{c}$ & $451: 4^{*}$ & 45 & $1: 4$ & & & $75,0 \%$ \\
\hline $\overrightarrow{0}_{0 \infty}^{0} . \widehat{\Omega}$ & I & $9 \mathrm{a}$ & $23-6^{*}$ & 23 & $3,4 \times 10^{-3} * *$ & 020 & $13,8 \%$ & $\begin{array}{c}\text { Similar ao PCE 102- } \\
6\end{array}$ \\
\hline$\stackrel{0}{\pi}$ & V & $10 \mathrm{a}$ & $102-2 *$ & 102 & $4,2 \times 10^{-4} * *$ & $0,2 \%$ & $46,3 \%$ & Menor \\
\hline & & $10 \mathrm{~b}$ & $102-6 *$ & 102 & $1,1 \times 10^{-3} * *$ & & $21,0 \%$ & Similar ao PCE 23-6 \\
\hline
\end{tabular}

Notas:

${ }^{1} \mathrm{Na}$ identificação dos aditivos, o primeiro número se refere ao tamanho da cadeia lateral, e a sequência de números, à continuação à relação cadeia lateral:grupos carboxílicos; assim, um aditivo identificado como 23-1:2 se refere a um polímero com tamanho de cadeia lateral igual a 23 e com uma cadeia lateral para cada 2 grupos carboxilicos livres. ${ }^{2}$ Número de lugares com carga aniônica por molécula.

${ }^{3}$ Porcentagem de sólidos do aditivo adicionada ao sistema em relação à massa do cimento. 
Os dados dessas pesquisas mostram que, para os polímeros com cadeias laterais de igual tamanho, porém densidade diferente, os de menor densidade de cadeias laterais geram os maiores incrementos na duração do período de indução e tempos de pega. Esse comportamento pode ser observado na Tabela 1, quando comparados entre si os resultados dos polímeros dos grupos $1,2,3,4,5$, 9, 12, 14 e 15. Contudo, o impacto do aditivo de densidade de cadeias laterais baixa diminui com o aumento do tamanho das cadeias laterais. Por exemplo, quando se passa de uma relação cadeia lateral:grupo carboxílico de 1:2 para 1:6, em polímeros com cadeia lateral com 23 repetições do grupo éter (linhas 1a e 1c), a duração do período de indução passa de $6 \mathrm{~h}$ a $22 \mathrm{~h}$ (diferença de $16 \mathrm{~h}$ ). Já quando o tamanho ou o número de repetições do grupo éter na cadeia lateral é de 102 (linhas 2a e 2c), a duração do período de indução para o aditivo de relação $1: 2$ é de $0,5 \mathrm{~h}$, e para o de relação $1: 6$, é de $3,5 \mathrm{~h}$ (diferença de $3 \mathrm{~h}$ ). Por outro lado, no caso de polímeros com igual densidade de cadeias laterais, quanto maior o tamanho da cadeia lateral, menor é o retardo gerado, o qual é observado quando comparados entre si os resultados dos grupos a, b, c, para o mesmo tipo de cimento.

Os comportamentos descritos acima estão diretamente relacionados com a capacidade do aditivo de se adsorver na superfície. Assim, os polímeros que apresentam os maiores teores de adsorção são os que prolongam a duração do período de indução e os tempos de pega em maior proporção. Na Tabela 2, se comparados entre si os teores adsorvidos dos polímeros dos grupos 1, 2, 3, 4, 6, 7, 8 e 10, é possível observar que, para polímeros com cadeias laterais de igual tamanho, quanto menor a densidade de cadeias laterais, maior é o teor adsorvido. Adicionalmente, quando comparados entre si os valores de adsorção dos polímeros dos grupos a, b e c, para o mesmo tipo de cimento, observa-se que, em aditivos com igual densidade de cadeias laterais, quanto menor seu tamanho, maior é a adsorção do polímero na superfície das partículas.

Os dados de Schmidt et al. (2011) (grupos 13, 14, 15 e 16, Tabela 1) são coerentes com os obtidos pelos outros autores quando utilizados em igual quantidade, contudo, quando utilizados na dosagem necessária para se atingir igual consistência, o fato de o PCE LC (polímero com baixa densidade de carga aniônica) precisar ser dosado em maior quantidade faz com que tanto os tempos de pega quanto a duração do período de indução sejam maiores do que para o PCE HC (polímero com alta densidade de carga aniônica).

Os aditivos com menor densidade de cadeias laterais possuem maior capacidade de adsorção por terem em sua estrutura maior quantidade de grupos carboxílicos não esterificados, retardando as reações em maior proporção. Quando as cadeias laterais são curtas, quanto menor o tamanho da cadeia lateral, menor será a massa molecular do polímero; como consequência, quando dosados em iguais quantidades em massa, maior número de moléculas estará presente se comparado aos aditivos com cadeias laterais maiores.

De fato, os resultados obtidos por Winnefeld et al. (2007a) para o polímero de ácido polimetacrílico sem cadeias laterais acopladas, em comparação com polímeros com cadeias laterais acopladas, evidenciam que a adsorção e o retardo gerado pelos PCE estão diretamente relacionados com o número de grupos carboxílicos livres presentes no sistema, dado que o maior retardo e a maior adsorção foram obtidos para o polímero de ácido polimetacrílico.

$\mathrm{O}$ teor de $\mathrm{C}_{3} \mathrm{~A}$ do cimento influi também no retardo gerado pelo aditivo, assim como em sua capacidade para se adsorver. Por um lado, quanto maior o teor de $\mathrm{C}_{3} \mathrm{~A}$ do cimento, menor é o retardo gerado, conforme pode ser observado na Tabela 1 quando comparados os resultados dos grupos I, II e III, para aditivos com igual estrutura molecular. Contudo, apesar de o policarboxilato retardar menos os cimentos com elevado teor de $\mathrm{C}_{3} \mathrm{~A}$, o teor adsorvido por esses cimentos é maior, comportamento que pode ser observado quando comparado, para polímeros com igual estrutura molecular (grupos a, b e c), o teor adsorvido pelos cimentos dos grupos I e II (baixo e alto teor de $\mathrm{C}_{3} \mathrm{~A}$ respectivamente). Esse comportamento é, de certa forma, contraditório, pois, conforme discutido previamente, para o mesmo tipo de cimento, o retardo está diretamente relacionado à quantidade adsorvida na superfície das partículas. Contudo, segundo Winnefeld et al. (2007b), apesar de o policarboxilato apresentar adsorção preferencial no $\mathrm{C}_{3} \mathrm{~A}$, retarda principalmente a hidratação do $\mathrm{C}_{3} \mathrm{~S}$. Devido a isso, em cimentos com elevado teor de $\mathrm{C}_{3} \mathrm{~A}$, maiores quantidades de aditivo ficam adsorvidas em sua superfície ou intercaladas em seus produtos de hidratação, restando menos aditivo disponível para interagir com as fases silicato e retardar sua hidratação.

Pourchet et al. (2007) observaram o efeito retardador do policarboxilato no $\mathrm{C}_{3} \mathrm{~S}$ por meio de ensaios de condutividade em suspensões diluídas de $\mathrm{C}_{3} \mathrm{~S}$, devido à diminuição da taxa de solubilidade em presença do PCE. Foi observado também que, quanto menor o grau de esterificação, ou seja, quanto menor a densidade de cadeias laterais dos aditivos utilizados, o retardo gerado é maior, pois policarboxilatos com baixo grau de 
esterificação, ou maior adsorção, impedem a dissolução do $\mathrm{C}_{3} \mathrm{~S}$ durante um longo período.

Ensaios de ressonância nuclear magnética, técnica a partir da qual é possível obter-se um indicativo da formação do gel C-S-H por comparação da quantidade de monômero (silicato anidro) e dímeros e polímeros (silicato polimerizado devido à formação do gel C-S-H), permitiram verificar que aditivos com elevada densidade de carga aniônica retardam a formação do gel C-S-H durante os primeiros 7 dias de hidratação, sem influência na quantidade formada após 28 dias (MORATTI; MAGAROTTO; MONTELLANO, 2011).

Em resumo, os dados da literatura analisada mostram que, se comparado o retardo gerado por quantidades iguais (em massa) de polímeros com cadeia lateral de igual tamanho, porém densidade de cadeias laterais diferentes, aqueles com menor densidade de cadeias laterais geram maior retardo, fenômeno mais acentuado quanto menor o tamanho da cadeia lateral. Por outro lado, quando a comparação é feita entre polímeros com igual densidade de cadeias laterais, porém com tamanhos diferentes, o maior retardo é gerado pelos polímeros que possuem as menores cadeias laterais.

Os dados de adsorção mostram que o retardo gerado pelos aditivos está diretamente relacionado à capacidade dele de ser adsorver nas partículas, já que, quanto menor a densidade de cadeias laterais e menor seu tamanho, maior é a adsorção. Contudo, quando comparados cimentos com composição química diferente, quanto maior o teor de $\mathrm{C}_{3} \mathrm{~A}$, maior será a quantidade de policarboxilato adsorvida, porém o retardo gerado será menor.

Os dados também mostram que, dependendo da estrutura molecular do aditivo, a quantidade necessária para se obter igual estado de dispersão pode variar e, com isso, um aditivo que apresenta o menor retardo, quando comparadas iguais quantidades em massa, pode apresentar maior retardo quando utilizado na quantidade necessária para se atingir igual estado de dispersão.

Esses dados coletados serviram de base para a interpretação da análise do efeito de dois policarboxilatos base de aditivos superplastificantes nacionais, realizada com a finalidade de se verificar se eles apresentam comportamento equivalente ao relatado na literatura internacional. Neste estudo, além de se comparar o efeito de quantidades iguais em massa de polímeros com estrutura molecular diferente, foi possível analisar o efeito da presença de igual número de moléculas e, como consequência, quantidades equivalentes de grupos carboxílicos livres na hidratação do cimento. Esta abordagem permite observar com maior facilidade que a capacidade de adsorção do polímero, que está diretamente relacionada à quantidade de grupos carboxílicos presentes no sistema, possui um papel fundamental na influência do policarboxilato na hidratação do cimento.

\section{Materiais e métodos}

\section{Cimento}

Foi utilizado um cimento $\mathrm{CP}$ V, cuja caracterização química está apresentada na Tabela 3, realizada segundo a norma NBR NM 10 Cimento Portland - Análise Química Disposições gerais (ABNT, 2004).

\section{Aditivos}

Os aditivos à base de policarboxilato utilizados nesta pesquisa, identificados como PCE-1 e PCE3 , consistem em policarboxilatos esterificados por um poliéter, cuja caracterização química e física se encontra na Tabela 4 e na Tabela 5. Para seu emprego foi adicionado $1,1 \mathrm{~g} / \mathrm{L}$ de um antiespumante à base de éster polioxialquileno alquiléter, 0,99 $\mathrm{g} / \mathrm{L}$ de um fungicida à base de isotiazolonas, e 3,33 $\mathrm{g} / \mathrm{L}$ de um biocida à base de isotiazolonas, com a finalidade de preservar a solução de policarboxilato de agentes microbiológicos e evitar a incorporação excessiva de ar nas pastas de cimento preparadas com os aditivos. A representação esquemática da estrutura molecular de cada um dos aditivos utilizados encontra-se na Figura 4.

Foi feita análise por espectrofotometria no infravermelho em um espectrofotômetro de infravermelho com transformada de Fourier (Nicolet iS10) marca Thermo Fisher Scientific, modelo Nicolet iS10. A análise dos materiais, secos a $105^{\circ} \mathrm{C}$, revelou a presença preponderante de éster de ácidos carboxílicos e alcoxilado.

$\mathrm{Na}$ Tabela 6 são apresentadas as principais ligações químicas encontradas no espectrograma dos aditivos PCE-1 e PCE-3.

Levando em consideração as massas moleculares dos aditivos em estudo, observa-se que $1 \mathrm{~g}$ do PCE-1 a $100 \%$ de sólidos contém 2,61 $\times 10^{19}$ moléculas, e o PCE-3, 4,44×10 ${ }^{19}$, ou seja, $1 \mathrm{~g}$ do PCE-3 contém 1,7 molécula a mais do que o PCE$1 \mathrm{e}$, consequentemente, maior quantidade de grupos carboxílicos nessa mesma proporção. 
Tabela 3 - Analise química do cimento (NBR NM 10)

\begin{tabular}{l|c}
\hline \multicolumn{1}{c|}{ DETERMINAÇÕES } & RESULTADOS EM \% \\
\hline Perda ao fogo $(\mathrm{PF})$ & 2,90 \\
Anidrido silícico $\left(\mathrm{SiO}_{2}\right)$ & 19,6 \\
Óxido de cálcio $(\mathrm{CaO})$ & 63,9 \\
Óxido de magnésio $(\mathrm{MgO})$ & 0,73 \\
Óxido férrico $\left(\mathrm{Fe}_{2} \mathrm{O}_{3}\right)$ & 2,99 \\
Óxido de alumínio $\left(\mathrm{Al}_{2} \mathrm{O}_{3}\right)$ & 5,34 \\
Anidrido sulfúrico $\left(\mathrm{SO}_{3}\right)$ & 3,44 \\
Óxido de sódio $\left(\mathrm{Na}_{2} \mathrm{O}\right)$ total & 0,09 \\
Óxido de potássio $\left(\mathrm{K}_{2} \mathrm{O}\right)$ total & 0,83 \\
Equivalente alcalino $\left(\mathrm{em} \mathrm{Na}_{2} \mathrm{O}\right)$ total & 0,63 \\
Óxido de sódio $\left(\mathrm{Na}_{2} \mathrm{O}\right)$ solúvel em água & 0,07 \\
Óxido de potássio $\left(\mathrm{K}_{2} \mathrm{O}\right)$ solúvel em água & 0,51 \\
Sulfeto $\left(\mathrm{S}^{2-}\right)$ & 0,07 \\
Óxido de cálcio livre $(\mathrm{CaO})$ & 2,35 \\
Resíduo insolúvel $(\mathrm{RI})$ & 0,52 \\
\hline
\end{tabular}

Nota: *equivalente alcalino $\left(e m \mathrm{Na}_{2} \mathrm{O}\right)=\% \mathrm{Na}_{2} \mathrm{O}+0,658 \times \% \mathrm{~K}_{2} \mathrm{O}$.

Tabela 4 - Caracterização física dos aditivos

\begin{tabular}{lcc}
\hline \multicolumn{1}{c}{ ENSAIO } & PCE-1 & PCE-3 \\
\hline Teor de sólidos - NBR 10908 (ABNT, 2008) (\%) & $39,8 \%$ & $39,6 \%$ \\
Viscosidade - Método do fabricante (mPa.s) & 110 & 134 \\
Densidade - NBR 10908 (ABNT, 2008) (ml/g) & 1,078 & 1,073 \\
\hline
\end{tabular}

Tabela 5 - Caracterização química dos aditivos

\begin{tabular}{lcc}
\hline \multicolumn{1}{c}{ PROPRIEDADE } & PCE-1 & PCE-3 \\
\hline Valor ácido - Método do fabricante (ml/g) & 9,2 & 13,06 \\
pH - NBR 10908 (ABNT, 2008) & 4,55 & 4,30 \\
Massa molecular Mw - Método do fabricante (g/mol) & 23000 & 13500 \\
Índice de polidispersão (PDI) - Método do fabricante & $\sim 2,0$ & $\sim 2,0$ \\
Cadeias laterais: grupos carboxila (y:x) - Método do fabricante & $1: 2$ & $1: 2$ \\
Massa molecular das cadeias laterais - Método do fabricante (g/mol) & 1000 & 500 \\
Comprimento das cadeias laterais (n) - Método do fabricante & 22 & 11 \\
\hline
\end{tabular}

Figura 4 - Representação esquemática da estrutura molecular dos polímeros PCE-1 e PCE-3

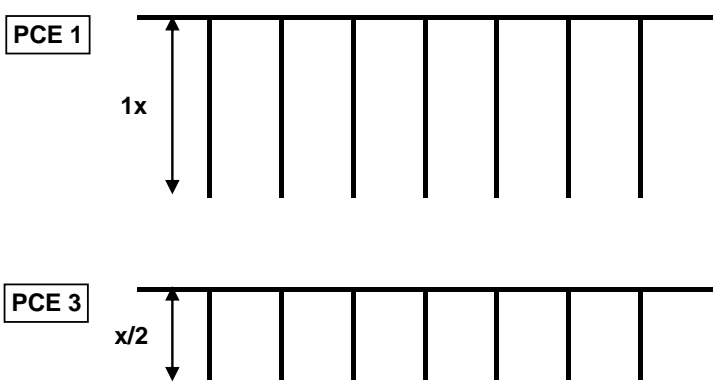

Tabela 6 - Principais ligações químicas

\begin{tabular}{c|c}
\hline $\mathbf{N}^{\mathbf{0}}$ de comprimento de onda $\left(\mathbf{c m}^{\mathbf{- 1}}\right)$ & Ligações químicas \\
\hline 2.870 & $\mathrm{C}-\mathrm{H}$ \\
1.730 & $\mathrm{C}=\mathrm{O}$ (éster) \\
1.100 & $\mathrm{C}-\mathrm{O}$ (alcoxilado e do éster) \\
\hline
\end{tabular}




\section{Calor de hidratação}

Foi utilizado um calorímetro de condução isotérmica Thermometric TAM AIR de oito canais, com sistema informatizado de aquisição de dados, onde a liberação de calor foi monitorada durante $72 \mathrm{~h}$. O calor liberado na hidratação do cimento é quantificado por meio da medição da diferença de temperatura entre a amostra e o meio circundante, mantida a temperatura constante, dando como resultado o fluxo de calor ou taxa de liberação de calor, em watts, ao longo do tempo.

Os ensaios foram realizados em pastas preparadas com relação água/cimento 0,34 , sem aditivo e com aditivos nas dosagens de $0,3 \%, 0,4 \%, 0,5 \%, 0,6 \%$, $0,7 \%, 0,8 \%$ e $1,0 \%$. Para preparação das pastas, a água foi colocada em um recipiente, e o cimento foi adicionado aos poucos, no período de $1 \mathrm{~min}$. A mistura foi feita manualmente, durante $2 \mathrm{~min}$, tempo após o qual as pastas foram colocadas no compartimento de ensaio. Nas pastas preparadas com aditivo, o mesmo foi previamente misturado à água de amassamento. Sendo a mistura manual, há perda do calor inicial, o que afeta o fluxo de calor registrado como primeiro pico.

Os valores de taxa de liberação de calor e calor total liberado, gerados pelo equipamento, foram recalculados em função do teor de cimento de cada uma das pastas e traçadas as curvas de fluxo de calor por quilo de cimento, expresso em W/kg, e o calor total liberado por quilo de cimento em função do tempo, expresso em $\mathrm{J} / \mathrm{kg}$.

\section{Análise Termogravimétrica (TG/DTG)}

Foram preparadas pastas de cimento de relação água/cimento 0,34 e dosagens de $0,0 \%, 0,5 \%$, $0,6 \%, 0,7 \%$ e $1,0 \%$ do aditivo PCE- 1 , e $0,0 \%$, $0,5 \%, 0,6 \%, 0,7 \%$ e $1,5 \%$ do PCE-3. Para a preparação das pastas, o cimento foi colocado aos poucos na água num tempo de $1 \mathrm{~min}$, tempo após o qual foi feita uma mistura manual durante $2 \mathrm{~min}$. Quando utilizado aditivo, o mesmo foi colocado junto com a água de amassamento.

Com a finalidade de se avaliar a influência do aditivo no tipo e na quantidade de hidratos formados ao longo do tempo, a hidratação das pastas preparadas foi interrompida após 2 h $27 \mathrm{~min}$ (correspondente ao momento de início do período de aceleração da pasta preparada sem aditivo determinado por meio de ensaios de calor de hidratação), 1 dia e 28 dias. A hidratação foi interrompida por meio de imersão das pastas em nitrogênio líquido para posterior liofilização durante 16 h, com a finalidade de se retirar a água livre presente na amostra no estado sólido.
Após a liofilização, as amostras foram submetidas a moagem e homogeneização em almofariz cerâmico e peneiradas em peneiras com abertura de $150 \mu \mathrm{m}$ e $75 \mu \mathrm{m}$, sendo, para realização dos ensaios, utilizada a fração passante pela peneira de $150 \mu \mathrm{m}$ e a retida na peneira, de $75 \mu \mathrm{m}$.

Para realização do ensaio foi utilizada uma termobalança analítica modelo STA 409 PG da Netzsch, utilizando-se uma taxa de aquecimento de $10^{\circ} \mathrm{C} / \mathrm{min}$ até $1.000{ }^{\circ} \mathrm{C}$ em ambiente de nitrogênio com taxa de $60 \mathrm{ml} / \mathrm{min}$. As amostras previamente preparadas foram acondicionadas em cadinho de alumina, pesadas em balança analítica e posicionadas no forno da termobalança; e os dados foram coletados automaticamente pelo computador que controla o equipamento.

\section{Resultados}

\section{Calor de hidratação}

Na Figura 5 são apresentadas as curvas de calor de hidratação da pasta pura e das pastas preparadas com 0,4\%, 0,5\%, $0,7 \%$ e $0,8 \%$ dos policarboxilatos PCE-1 e PCE-3. Observa-se que, para todas as dosagens utilizadas, há retardo das reações, com aumento da duração do período de indução. Por outro lado, quando utilizados em igual dosagem em relação à massa de cimento, o PCE-3 incrementa a duração do período de indução em maior proporção que o PCE-1.

O maior retardo gerado pelo aditivo PCE-3, quando comparado com dosagens iguais do PCE1, é consequência de sua menor massa molecular, dado que $1 \mathrm{~g}$ do PCE-3 contém 1,7 molécula a mais do que o PCE-1 e, consequentemente, maior quantidade de grupos carboxílicos nessa mesma proporção, responsáveis pelo retardo das reações de hidratação.

Esse fenômeno foi comprovado pela comparação das curvas de calor de hidratação obtidas com cada um dos policarboxilatos, quando dosados em quantidades equivalentes em termos do número de moléculas presentes no sistema e, como consequência, da densidade de carga aniônica. Os resultados obtidos estão apresentados na Figura 6.

Observa-se que, comparadas quantidades equivalentes dos aditivos PCE-1 e PCE-3, em termos do número de moléculas presentes no sistema, as curvas de calor de hidratação são equivalentes, comprovando-se, assim, que o fator da estrutura molecular do policarboxilato que determina seu efeito retardador é a densidade de carga aniônica. 
Figura 5 - Curvas de calor de hidratação da pasta de cimento pura e de pastas preparadas com diferentes dosagens do PCE-1 e PCE-3 - comparativo da influência dos aditivos, quando utilizados em igual quantidade, na hidratação do cimento
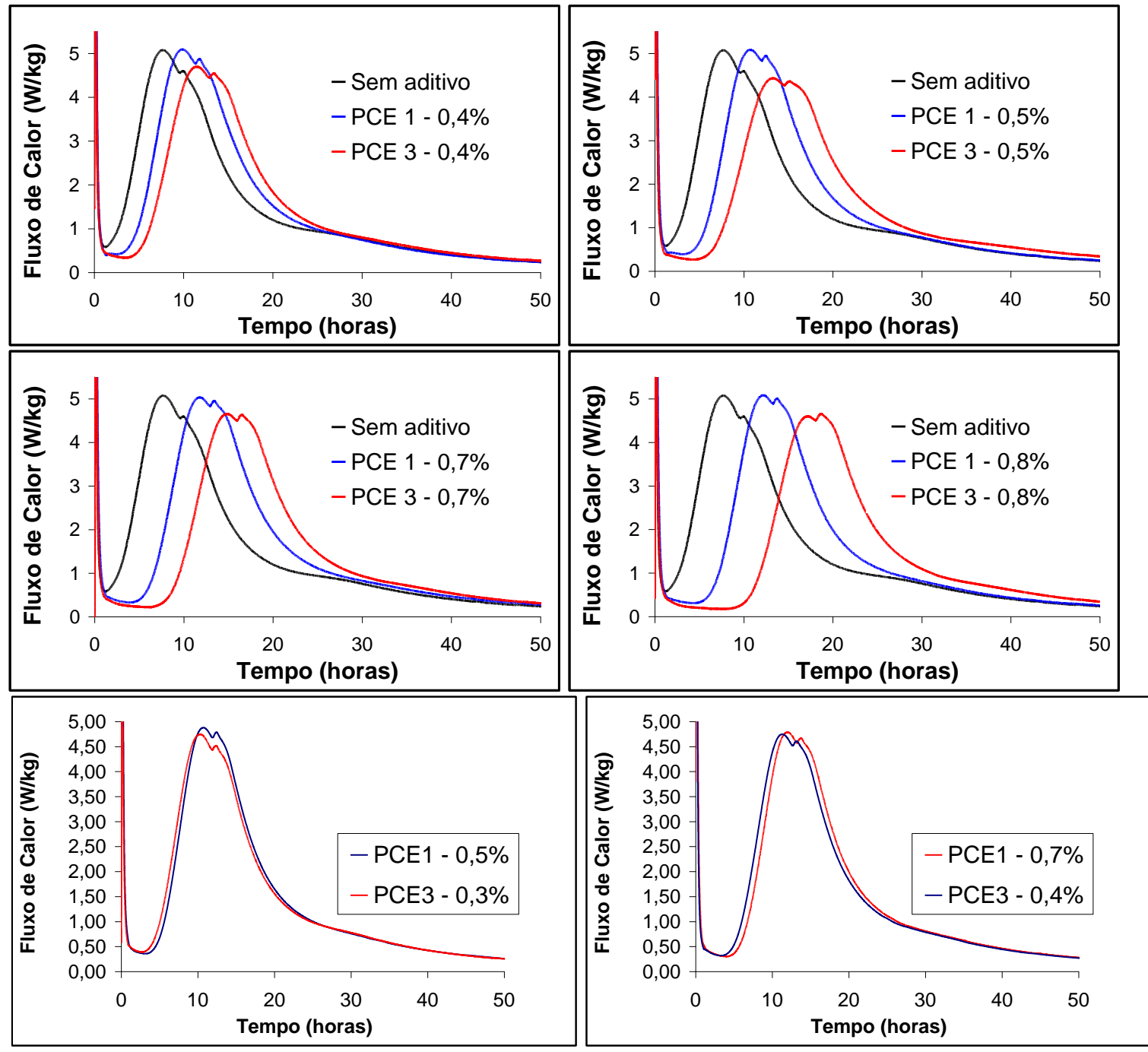

Figura 6 - Curvas de calor de hidratação obtidas com os policarboxilatos PCE-1 e PCE-3 quando utilizados em dosagens equivalentes em termos do número de moléculas e densidade de carga aniônica presente no sistema

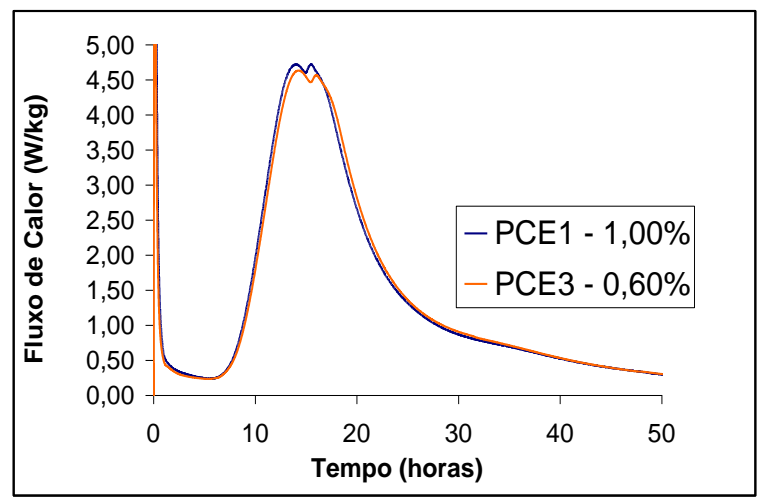




\section{Análise Termogravimétrica (TG/DTG)}

As reações de transformação que ocorrem ao longo do ensaio são de desidratação dos hidratos formados e de volatilização de $\mathrm{CO}_{2}$, cada um dos quais correspondente a uma etapa de perda de massa nas curvas TG, em determinada faixa de temperatura. A partir da primeira derivada das curvas TG é possível se caracterizar melhor a faixa de temperatura na qual acontece a perda de massa e identificar o composto relativo a ela, já que cada um deles possui uma temperatura de pico típica. Segundo Taylor (1998), numa pasta de cimento Portland curada durante 14 meses, a perda de massa entre $425^{\circ} \mathrm{C}$ e $550{ }^{\circ} \mathrm{C}$ corresponde à decomposição da portlandita; perdas acima de 550 ${ }^{\circ} \mathrm{C}$ correspondem, em parte, à liberação de $\mathrm{CO}_{2}$ presente por prévia carbonatação da amostra ou presença de fíler calcário no cimento e, em parte, aos últimos estágios da decomposição do C-S-H.
As perdas observadas antes do pico da portlandita correspondem à decomposição do C-S-H $\left(115^{\circ} \mathrm{C}\right.$ a $\left.125^{\circ} \mathrm{C}\right)$, da gipsita $\left(145^{\circ} \mathrm{C}\right.$ a $\left.165^{\circ} \mathrm{C}\right)$ e das fases aluminato hidratadas, etringita $\left(135^{\circ} \mathrm{C}\right.$ a $\left.140^{\circ} \mathrm{C}\right) \mathrm{e}$ monossulfoaluminato $\left(185^{\circ} \mathrm{C}\right.$ a $\left.200^{\circ} \mathrm{C}\right)$.

$\mathrm{Na}$ análise de resultados foram identificados três ou quatro picos principais, dependendo do tempo de hidratação da pasta em questão e da presença ou não de aditivo, cuja nomenclatura está indicada no Quadro 1. Os picos CE e G apresentam sobreposição, por isso, para o cálculo da perda referente a cada um, foi utilizada a ferramenta da deconvolução de picos.

Na Figura 7 estão apresentadas as curvas TG e DTG obtidas com as pastas de cimento preparadas com o aditivo PCE-1, cuja hidratação foi interrompida 2 h e 27 min após o contato da água com o cimento. Na Figura 8 são apresentadas as curvas obtidas para o aditivo PCE-3.

Quadro 1 - Nomenclatura dos picos da DTG e compostos relacionados

\begin{tabular}{|c|l|}
\hline Pico & \multicolumn{1}{|c|}{ Compostos relacionados } \\
\hline \multirow{2}{*}{ CE } & C-S-H \\
\cline { 2 - 2 } & Aluminatos de cálcio hidratados \\
\cline { 2 - 2 } & Etringita \\
\hline \multirow{2}{*}{ G } & Sulfato de cálcio (gipsita ou hemidrato) \\
\cline { 2 - 2 } & Monossulfoaluminato \\
\hline P & Portlandita \\
\hline C & Calcita \\
\hline
\end{tabular}

Figura 7 - Curvas TG e DTG de pastas de cimento preparadas com diferentes dosagens do aditivo PCE-1 cuja hidratação foi interrompida 2 h e 27 min após o contato da água com o cimento

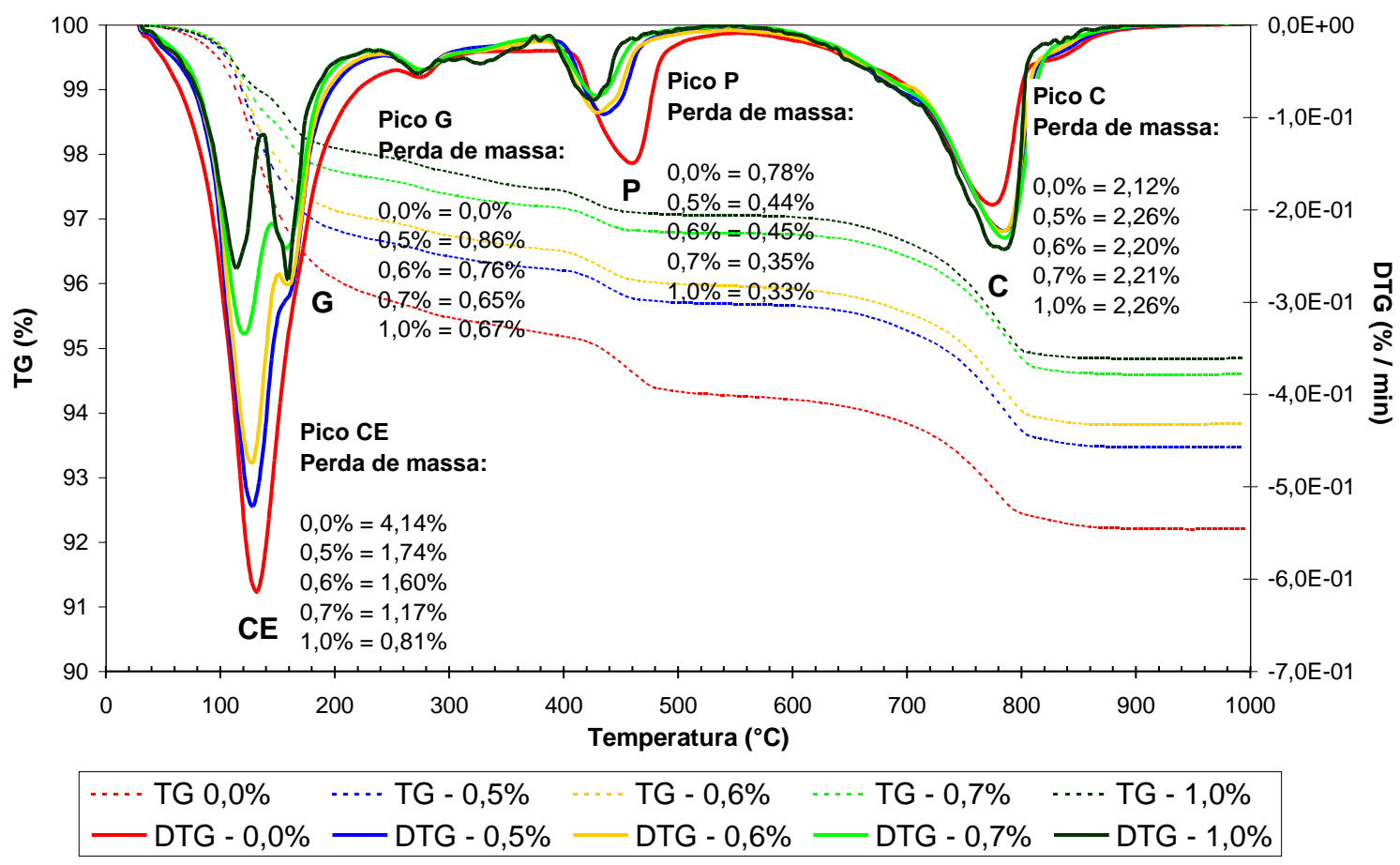

278 Rojas, C. M.; Cincotto, M. A. 
Figura 8 - Curvas TG e DTG de pastas de cimento preparadas com diferentes dosagens do aditivo PCE-3 cuja hidratação foi interrompida 2 h e 27 min após o contato da água com o cimento

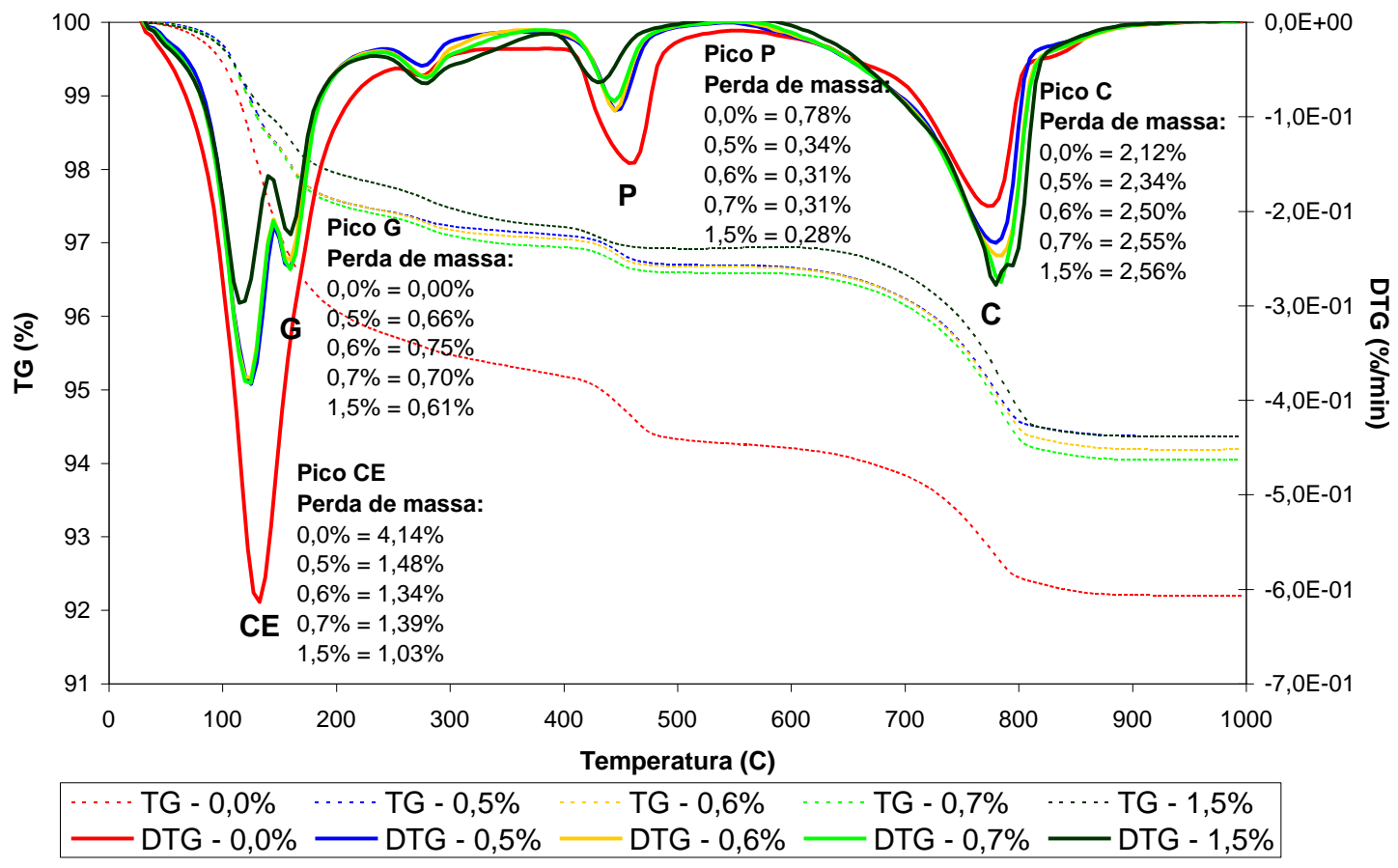

Observa-se menor intensidade nos picos $\mathrm{CE}$ e $\mathrm{P}$ quando utilizados os dois aditivos, indicando retardo na formação do $\mathrm{C}-\mathrm{S}-\mathrm{H}$, da etringita e da portlandita, tanto mais quanto maior a dosagem do aditivo. Nos dois casos, quando utilizado o aditivo, é possível se observar o pico $\mathrm{G}$, associado à decomposição do sulfato de cálcio (gipsita ou hemidrato) em conjunto com monossulfoaluminato de cálcio, evidenciando retardo na dissolução do sulfato por interferência do policarboxilato. Também é possível se verificar que, utilizadas as dosagens de $0,5 \%$ e $0,6 \%$, o retardo na formação do C-S-H e da etringita gerado pelo aditivo PCE-3 é maior do que o gerado pelo PCE-1. Em relação à portlandita, o retardo gerado pelo PCE-3 é maior para todas as dosagens.

Na Figura 9, referente às pastas preparadas com o aditivo PCE-1 cuja hidratação foi interrompida após $24 \mathrm{~h}$, não se pode observar que nenhuma das dosagens utilizadas gerou retardo na formação do $\mathrm{C}-\mathrm{S}-\mathrm{H}$, etringita ou portlandita, e que, de forma contrária, dependendo da dosagem utilizada, em alguns casos, a intensidade dos picos $\mathrm{CE}$ e $\mathrm{P}$ foi levemente inferior na da pasta de referência. No caso do aditivo PCE-3 (Figura 10), é possível se observar uma leve diminuição na quantidade de portlandita formada quando utilizadas as dosagens de $0,5 \%, 0,6 \%$ e $0,7 \%$. No caso da utilização da dosagem de $1,5 \%$, a quantidade de C-S-H, etringita e portlandita formada foi significativamente inferior em relação à pasta preparada sem aditivo, indicando que, após $24 \mathrm{~h}$, esta dosagem ainda apresenta influência na hidratação do cimento.

Nas Figuras 11 e 12 são apresentadas as curvas TG e DTG das pastas de cimento após 28 dias de hidratação, nas quais não é possível se observarem diminuições significativas na quantidade de C-S$\mathrm{H}$, etringita e portlandita formadas como consequência da utilização dos aditivos PCE-1 e PCE-3, indicando que a influência dos policarboxilatos em estudo é apenas significativa nas primeiras horas de hidratação. 
Figura 9 - Curvas TG e DTG de pastas de cimento preparadas com diferentes dosagens do aditivo PCE-1 cuja hidratação foi interrompida $24 \mathrm{~h}$ após o contato da água com o cimento

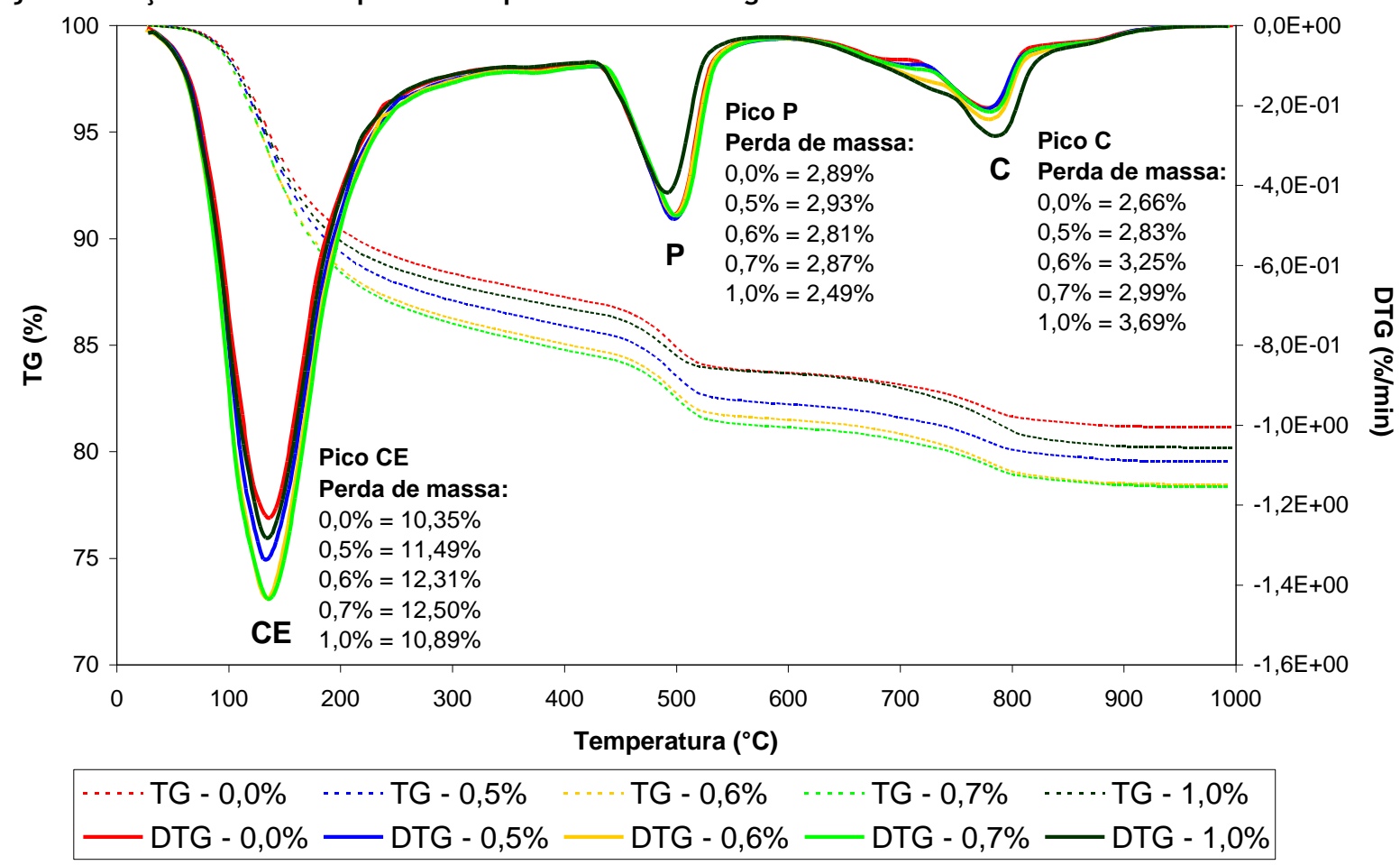

Figura 10 - Curvas TG e DTG de pastas de cimento preparadas com diferentes dosagens do aditivo PCE-3 cuja hidratação foi interrompida $24 \mathrm{~h}$ após o contato da água com o cimento

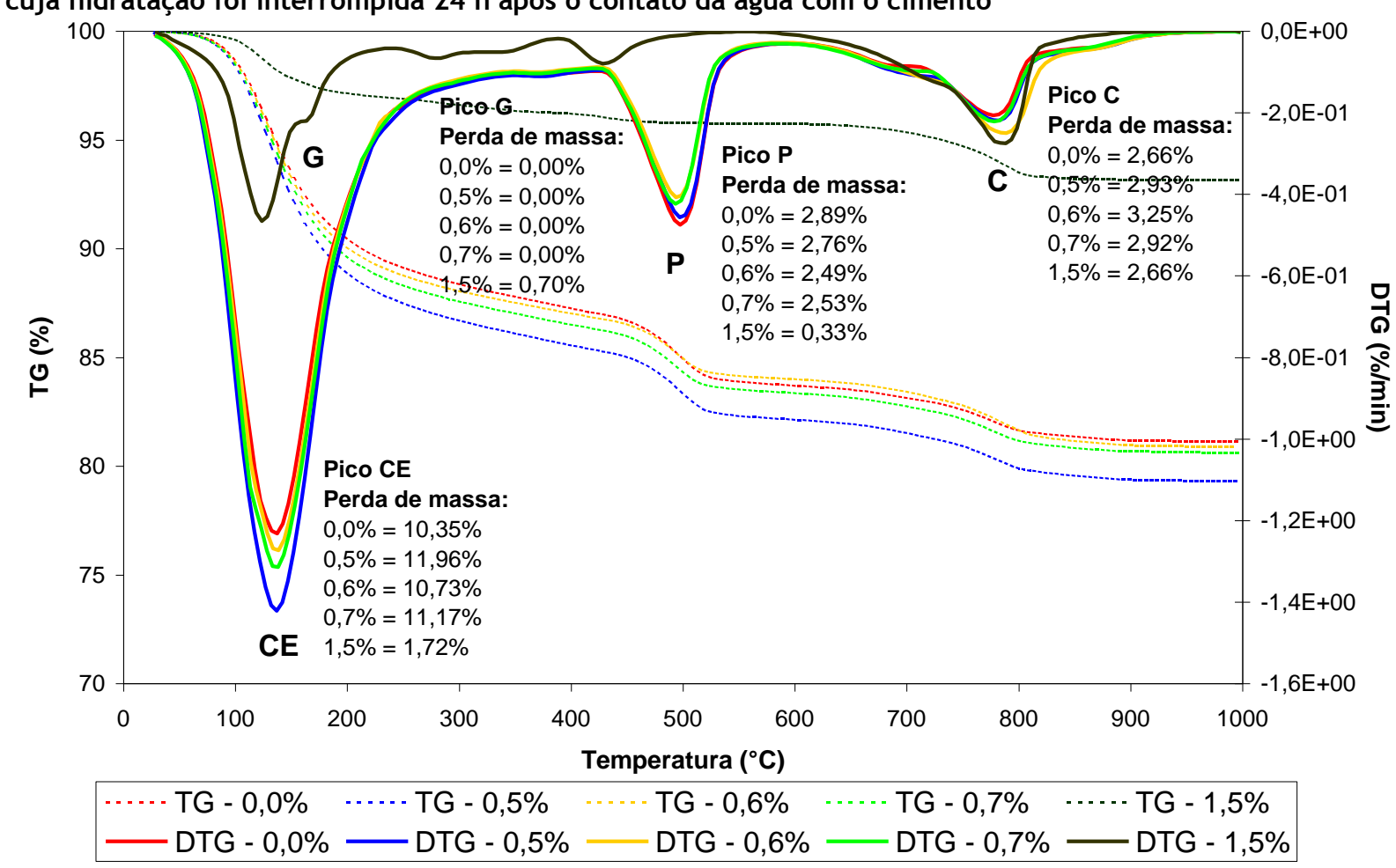


Figura 11 - Curvas TG e DTG de pastas de cimento preparadas com diferentes dosagens do aditivo PCE-1 cuja hidratação foi interrompida 28 dias após o contato da água com o cimento

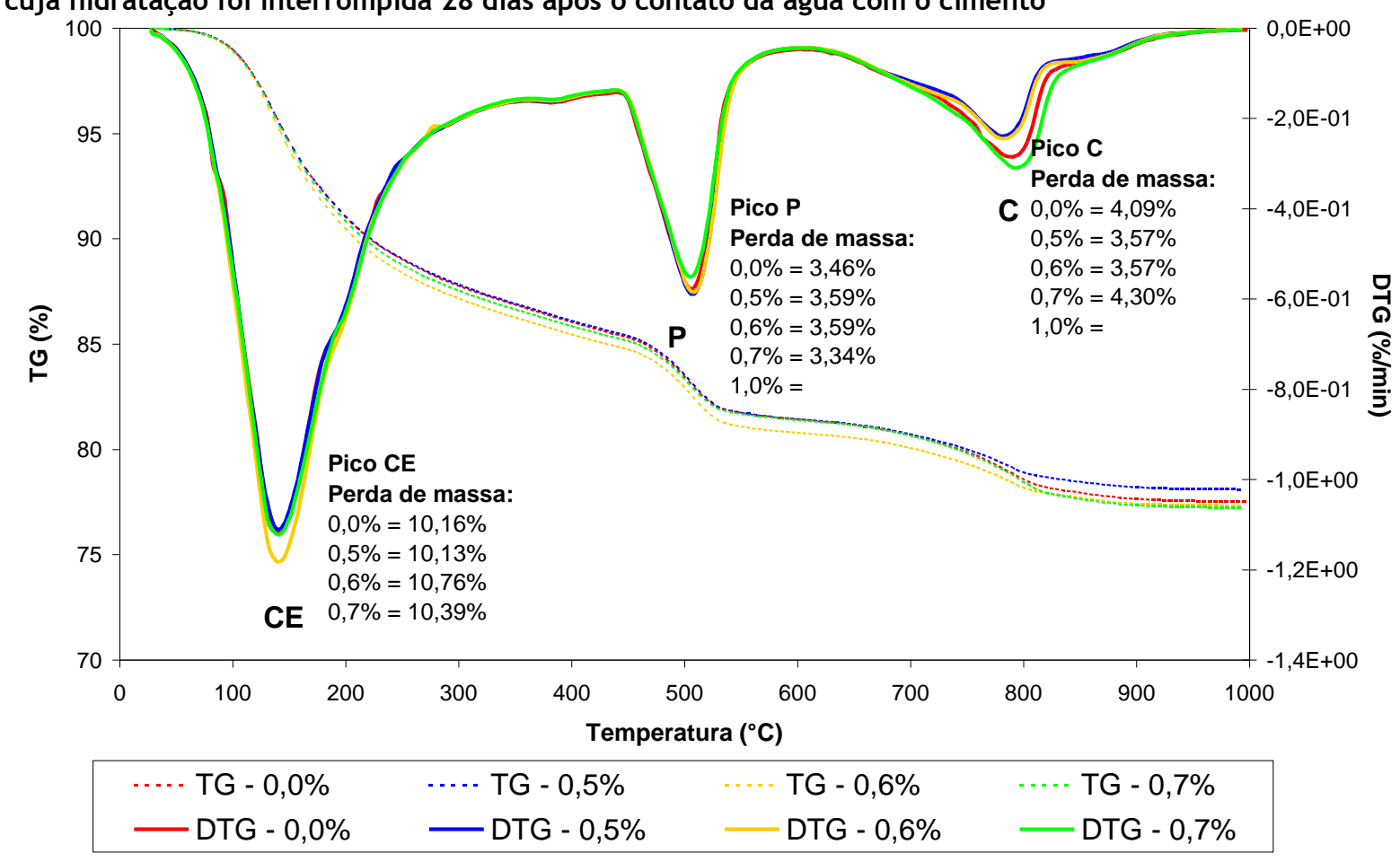

Figura 12 - Curvas TG e DTG de pastas de cimento preparadas com diferentes dosagens do aditivo PCE-3 cuja hidratação foi interrompida 28 dias após o contato da água com o cimento

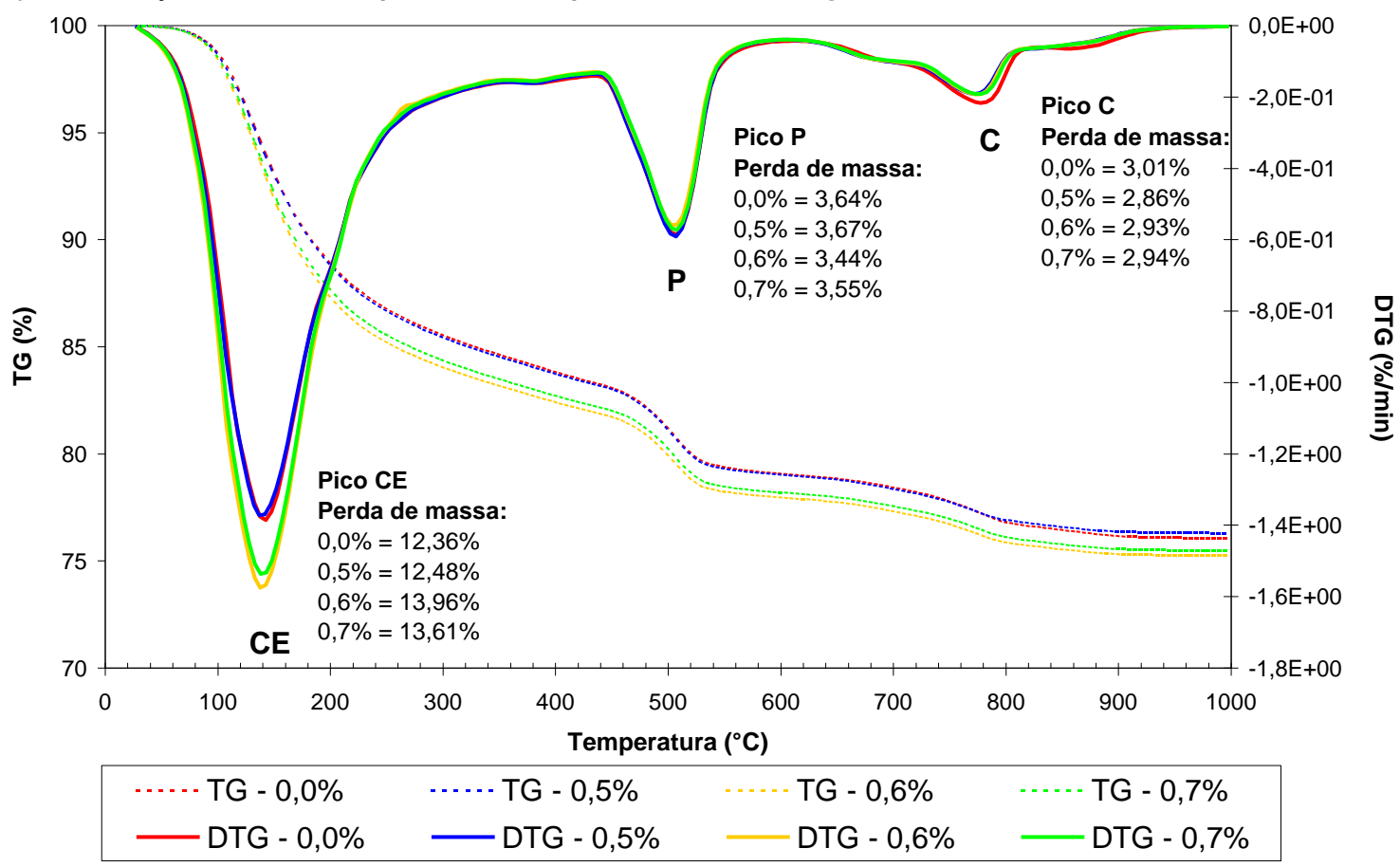




\section{Conclusões}

Os aditivos à base de policarboxilato retardam as reações de hidratação do cimento durante as primeiras horas, sem influência do tipo e da quantidade de hidratos formados em idades avançadas.

O grau de retardo gerado por determinado policarboxilato depende de sua estrutura molecular. Quando utilizados em igual quantidade em massa, polímeros com cadeias laterais pequenas, e com menor densidade, apresentam o maior grau de retardo, fenômeno associado à quantidade de grupos carboxílicos livres presentes no sistema. As cadeias menores e em maior número recobrem mais eficientemente a superfície das partículas de cimento, retardando sua hidratação.

A comparação de curvas de calor de hidratação de pastas de cimento preparadas com dosagens equivalentes, em termos da densidade de carga aniônica, de policarboxilatos com estrutura molecular diferente, reafirmou o fato de a adsorção e o consequente retardo estarem associados à quantidade de grupos carboxílicos livres presentes no sistema.

\section{Referências}

ASSOCIAÇÃO BRASILEIRA DE NORMAS TÉCNICAS. NBR 10908: aditivos para argamassa e concreto: ensaios de caracterização. Rio de Janeiro, 2008.

\section{ASSOCIAÇÃO BRASILEIRA DE NORMAS TÉCNICAS. NBR NM 10: cimento Portland: análise química: disposições gerais. Rio de Janeiro, 2004.}

ALONSO, M. M. et al. Influência de la Estructura de Aditivos Basados en Policarboxilato Sobre el Comportamiento Reológico de Pastas de Cemento. Materiales de Construcción, v. 57, n. 286, p. 6581, abr./jun. 2007.

CHANDRA, S.; BENSTED, J.; BARNES, P. (Eds.). Structure and Performance of Cements. London: Spon Press, 2002. p. 141-181.

FARRINGTON, S. A. Evaluating the Effect of Mixing Method on Cement Hydration in the Presence of Polycarboxylate High-Range Water Reducing Admixture by Isothermal Conduction Calorimetry. In: INTERNATIONAL CONGRESS ON THE CHEMESTRY OF CEMENT, 12., Montreal, 2007. Proceedings... 2007.

FLATT, R. J. et al. Conformation of Adsorbed Comb Copolymer Dispersants. Langmuir, v. 25, p. 845-855, 2009.
GRIESSER, A. Cement: superplasticizer interactions at ambient temperatures. Zurich, 2002. $147 \mathrm{f}$. Tese (Doutorado) - Swiss Federal Institute of Technology Zurich, 2002.

HUI, W. et al. Research on Synthesis and Action Mechanism of Polycarboxylate Superplasticizer. Frontiers of Chemistry in China, v. 2, p. 322325, 2007.

KOIZUMI, K.; UMEMURA, Y.; TSUYUKI, N. Effects of Chemical Admixtures on Silicate Structure of Hydrated Portland Cement. In: INTERNATIONAL CONGRESS ON THE CHEMISTRY OF CEMENT, 12., Montreal, 2007. Proceedings... Madrid, 2007.

LOTHENBACH, B.; WINNEFELD, F.; FIGI,R. The Influence of Superplasticizers on the Hydration of Portland Cement. In:

INTERNATIONAL CONGRESS ON THE CHEMISTRY OF CEMENT, 12., Montreal, 2007. Proceedings... Montreal, 2007.

MACAR,J.M.; CHAN,G.W. Derivate Conduction Calorimetry. In: INTERNATIONAL CONGRESS ON THE CHEMISTRY OF CEMENT, 12., Montreal, 2007. Proceedings... Montreal, 2007.

MORATTI, F.; MAGAROTTO, R.;

MANTELLATO, S. Influence of Polycarboxylate Side Chains Length on Cement Hydration and Strengths Development In: INTERNATIONAL CONGRESS ON THE CHEMISTRY OF CEMENT, 13., Madrid, 2011. Proceedings... Madrid, 2011.

PLANK, J. et al. Synthesis and Performance of Methacrylic Ester Based Polycarboxylate Superplasticizers Possessing Hydroxyl Terminated Ppoly (Ethylene Glycol) Side Chains. Cement and Concrete Research, v. 38, p. 1210-1216, 2jan. 2008.

PLANK, J.; SACHSENHAUSER, B.

Experimental Determination of the Effective Anionic Charge Density of Polycarboxylate Superplasticizers in Cement Pore Solution.

Cement and Concrete Research, v. 39, p. 1-5, 2009.

PUERTAS, F.; VAZQUEZ, T. Hidratación Inicial del Cemento: efecto de aditivos superplastificantes. Materiales de Construcción, v. 51, p. 53-61, 2001.

POURCHET, S. et al. Influence of PC

Superplasticizers on Tricalcium Silicate Hydration. In: INTERNATIONAL CONGRESS ON THE CHEMISTRY OF CEMENT, 12., Montreal, 2007. Proceedings... Montreal, 2007. 
RÖßLER, C.; MÖSER, B.; STARK, J. Influence of Superplasticizers on $\mathrm{C}_{3} \mathrm{~A}$ Hydration and Ettringite Growth in Cement Paste. In: INTERNATIONAL CONGRESS ON THE CHEMISTRY OF CEMENT, 12., Montreal, 2007. Proceedings... Montreal, 2007.

SAKAI, E. et al. Influence of Superplasticizers on the Hydration of Cement and the Pore Structure of Hardened Cement. Cement and Concrete Research, v. 36, p. 2049-2053, sep. 2006.

SCHMIDT, W. et al. Correlation Between Setting, Heat Evolution, and Deformations of Cementitious Binder Systems Depending on Type and Amount of Superplasticizer. In: INTERNATIONAL CONGRESS ON THE CHEMISTRY OF CEMENT, Madrid, 13., 2011. Proceedings... Madrid, 2011.

TAYLOR, H. F. W. Cement Chemistry. $2^{\text {nd }}$ ed. London: Thomas Telford, 1998. 113 p.

UCHIKAWA, H.; HANEHARA, S.; SAWAKI, D. The Role of Steric Repulsive Force in the Dispersion of Cement Particles in Fresh Paste Prepared With Organic Admixture. Cement and Concrete Research, v. 27, p. 37-50, 1997.

WINNEFELD, F. et al. Interaction of Polycarbolylate-Based Superplasticizer and Cements: influence of polymer structure and $\mathrm{C}_{3} \mathrm{~A}$ content of cement. In: INTERNATIONAL CONGRESS ON THE CHEMISTRY OF CEMENT, 12., Montreal, 2007. Proceedings... Montreal, 2007b.

WINNEFELD, F.; FIGI, R. The Influence of Superplasticizers on the Hydration of Portland Cement. In: INTERNATIONAL CONGRESS ON THE CHEMISTRY OF CEMENT, 12., Montreal, 2007. Proceedings... Montreal, 2007.
WINNEFELD, F. et al. Effects of the Molecular Architecture of Comb-Shaped Superplasticicers on Their Performance in Cementitious Systems.

Cement and Concrete Composites, v. 29, p. 251262, 2007a.

YOSHIOKA, K. et al. Adsorption Characteristics of Superplasticizers on Cement Component Minerals. Cement and Concrete Research, v. 32, p. 1507-1513, mar. 2002.

ZINGG, A. et al. The Microstructure of Dispersed and Non-Dispersed Fresh Cement Pastes: new insight by cryo-microscopy. Cement and Concrete Research, v. 38, p. 522-529, 2008a.

ZINGG, A. Cement-Superplasticizer Interaction: link between macroscopic phenomena and microstructural data of the early cement hydration. Zurich, 2008. $150 \mathrm{f}$. Tese (Doutorado em Engenharia Civil) - Swiss Federal Institute of Technology Zurich, Zwitzerland, 2008.

ZINGG, A. et al. Adsorption of Polyelectrolytes and Its Influence on the Rheology, Zeta Potential, and Microstructure of Various Cement and Hydrate Phases. Cement and Concrete Reseach, v. 323, p. 301-312, abr. 2008b.

ZINGG, A. et al. Interaction of PolycarboxylateBased Superplasticizers With Cements Containing Different C3A Amounts. Cement and Concrete Composites, v. 31, p. 153-162, jan. 2009.

\section{Agradecimentos}

Os autores agradecem à Sika S.A. do Brasil e ao Conselho Nacional de Desenvolvimento Científico e Tecnológico o financiamento da presente pesquisa.

Trabalho desenvolvido enquanto Carolina M. Rojas era funcionária da empresa Sika S.A. do Brasil.

\section{Carolina Martínez}

Escola Politécnica, Departamento de Engenharia de Construção Civil | Universidade de São Paulo | Av. Prof. Almeida Prado, 83, Travessa 2, Cidade Universitária | Caixa Postal 61548 | São Paulo - SP - Brasil | CEP 05508900 | Tel.: (11) 998888188 | E-mail: cmr352000@gmail.com

Maria Alba Cincotto

Escola Politécnica, Departamento de Engenharia de Construção Civil | Universidade de São Paulo | Tel.: (11) 3091 -5792

E-mail: cincotto@poli.usp.br

\section{Revista Ambiente Construído}

Associação Nacional de Tecnologia do Ambiente Construído

Av. Osvaldo Aranha, $99-3^{\circ}$ andar, Centro

Porto Alegre - RS - Brasil

CEP $90035-190$

Telefone: +55 (51) 3308-4084

Fax: +55 (51) 3308-4054

www.seer.ufrgs.br/ambienteconstruido

E-mail: ambienteconstruido@ufrgs.br 